\title{
Endoscopic treatment of a duodenal invagination
}
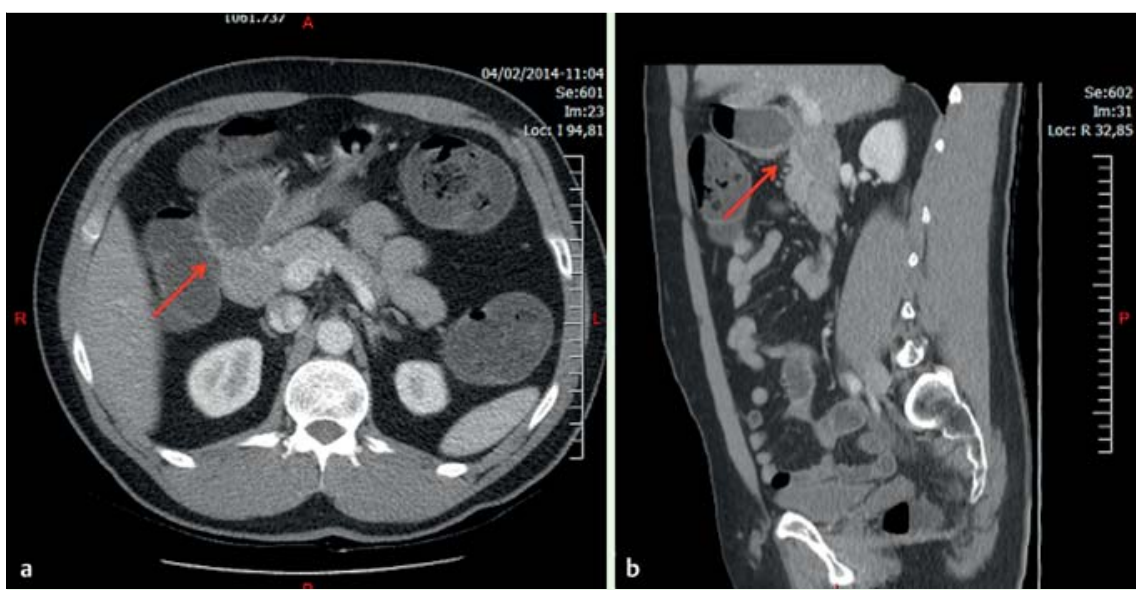

Fig. 1 Duodenal invagination in a 47-year-old man. Computed tomography showed a partial invagination at the junction between the bulb and the second duodenal portion (red arrows), with no vascular abnormalities: a axial view; b sagittal view.

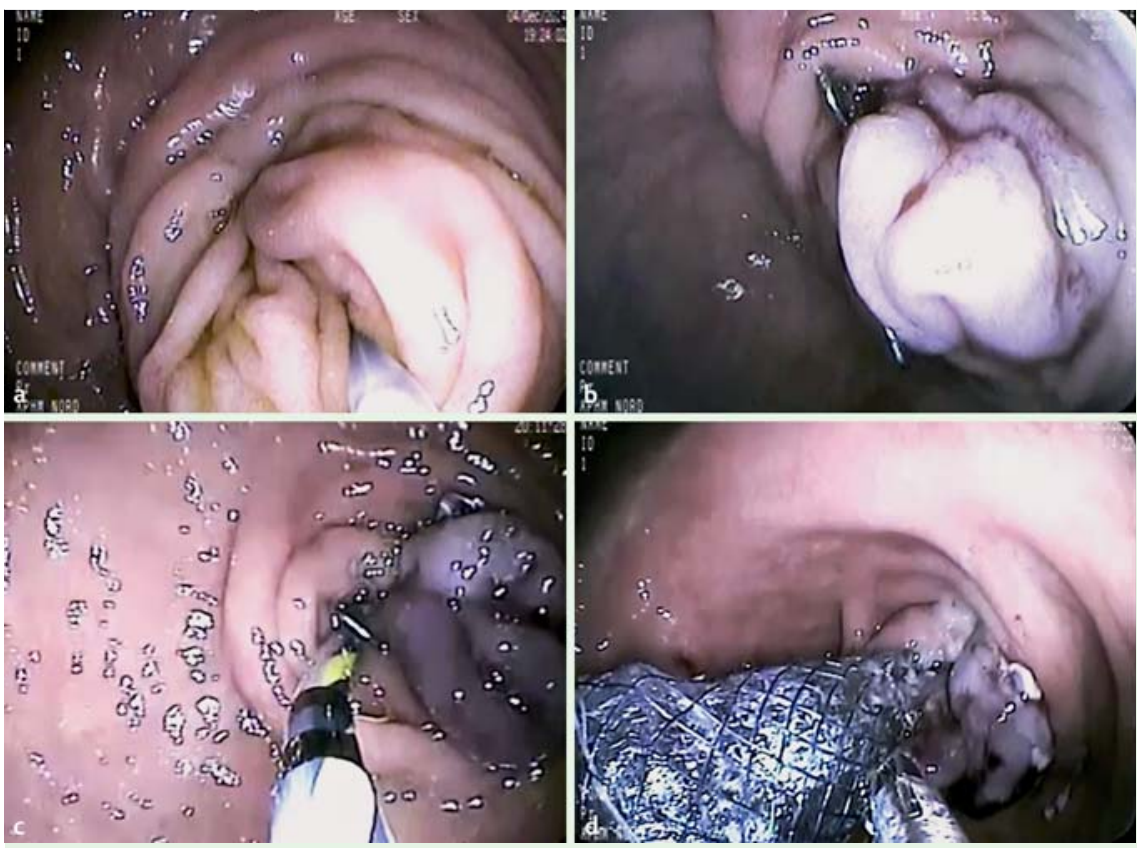

Fig. 2 Endoscopic treatment of duodenal invagination: first step. a Endoscopic view of the invagination. b, c Over-the-scope clips were deployed. d Clipping of the fully covered metallic stent.

A 47-year-old man was referred to North Hospital with a 2-month history of recurrent occlusive syndrome. Findings on computed tomography scan ( $\bullet$ Fig. 1 ) and endoscopy led to a diagnosis of duodenal invagination and partial duodenal atresia. Endoscopic therapy was performed ( $\bullet$ Video 1 ).

In the first endoscopic step ( $\bullet$ Fig. 2 ), two 12/6t over-the-scope clips (OTSC; Ovesco

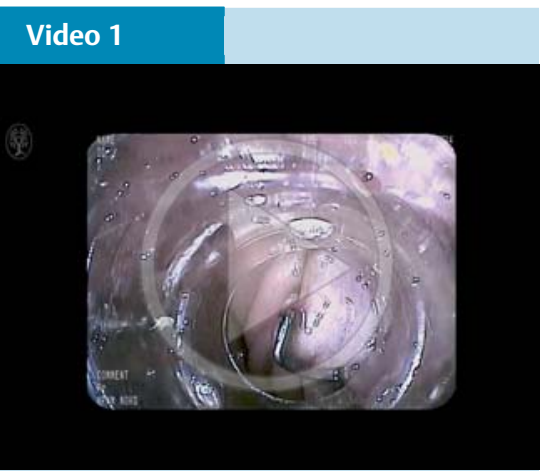

Endoscopic management of a duodenal invagination. Step 1: over-the-scope clip placement; enteric stent deployment and fixation. Step 2: endoscopic mucosal resection of duodenal mucosa; new stent deployment. Step 3: new endoscopic mucosal resection of the remaining invaginated mucosa; duodenal lumen patency.

In the second step 6 weeks later, the stent was retrieved, and migration of the OTSCs was confirmed. Necrosis of the duodenal folds was also apparent. A mucosal protrusion remained, affecting one-third of the duodenal circumference. Thus, an endoscopic mucosectomy was performed (the mucosa was found to be histpathologically normal) ( Fig.3). A new similar metallic stent was inserted and fixed in place with clips.

In the third and final procedure 8 weeks after the previous step, the stent was removed and an inflammatory area was dilated using an 18-20mm controlled radial expansion balloon (CRE; Boston Scientific, Marlborough, USA). A mucosectomy of an invaginated growth involving one-quarter of the circumference of the second duodenal portion completed the procedure ( $\bullet$ Fig.4), resulting in complete patency of the duodenal lumen.

At 3-month follow-up, symptom remission had been achieved: the patient had not suffered new occlusive episodes, had not required emergency department admission, and had no abdominal distension.

Endoscopy_UCTN_Code_TTT_1AT_2AC

Competing interests: None 

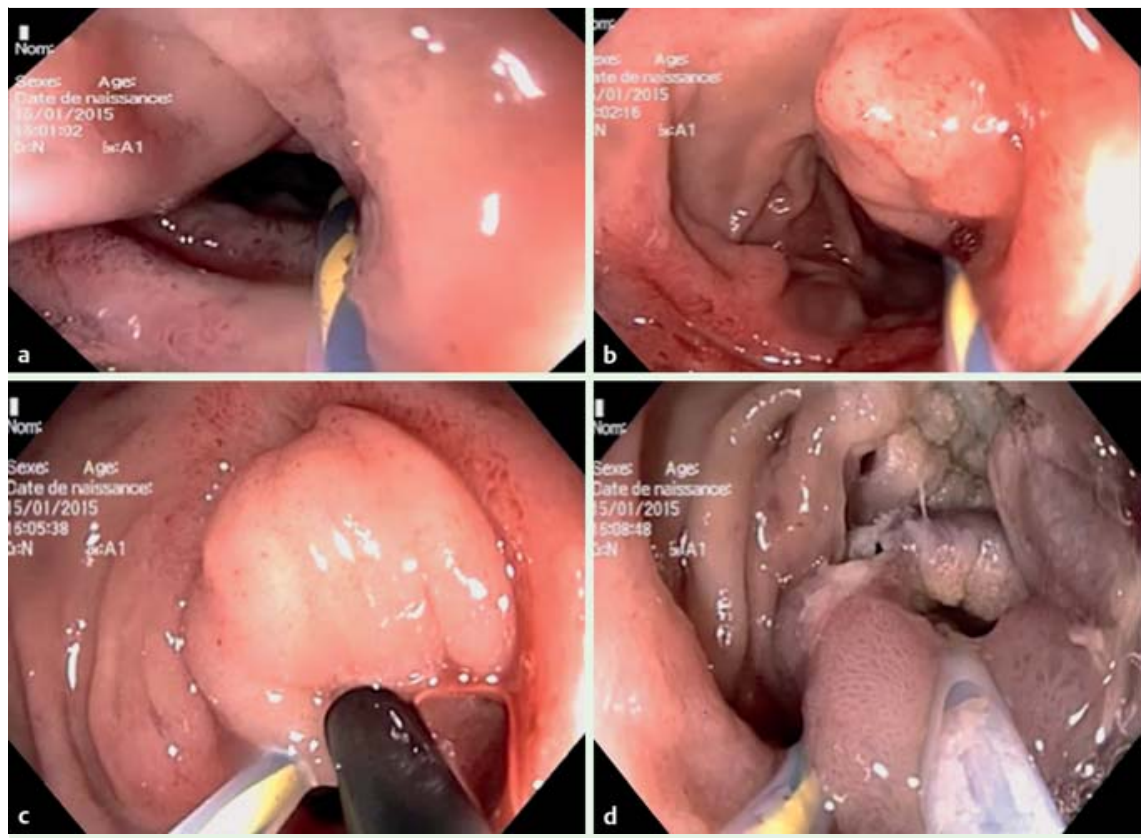

Fig. 3 Second step of endoscopic treatment, 6 weeks after the procedure shown in $\bullet$ Fig. 2. Endoscopic mucosal resection of a mucosal protrusion affecting one-third of the duodenal circumference.
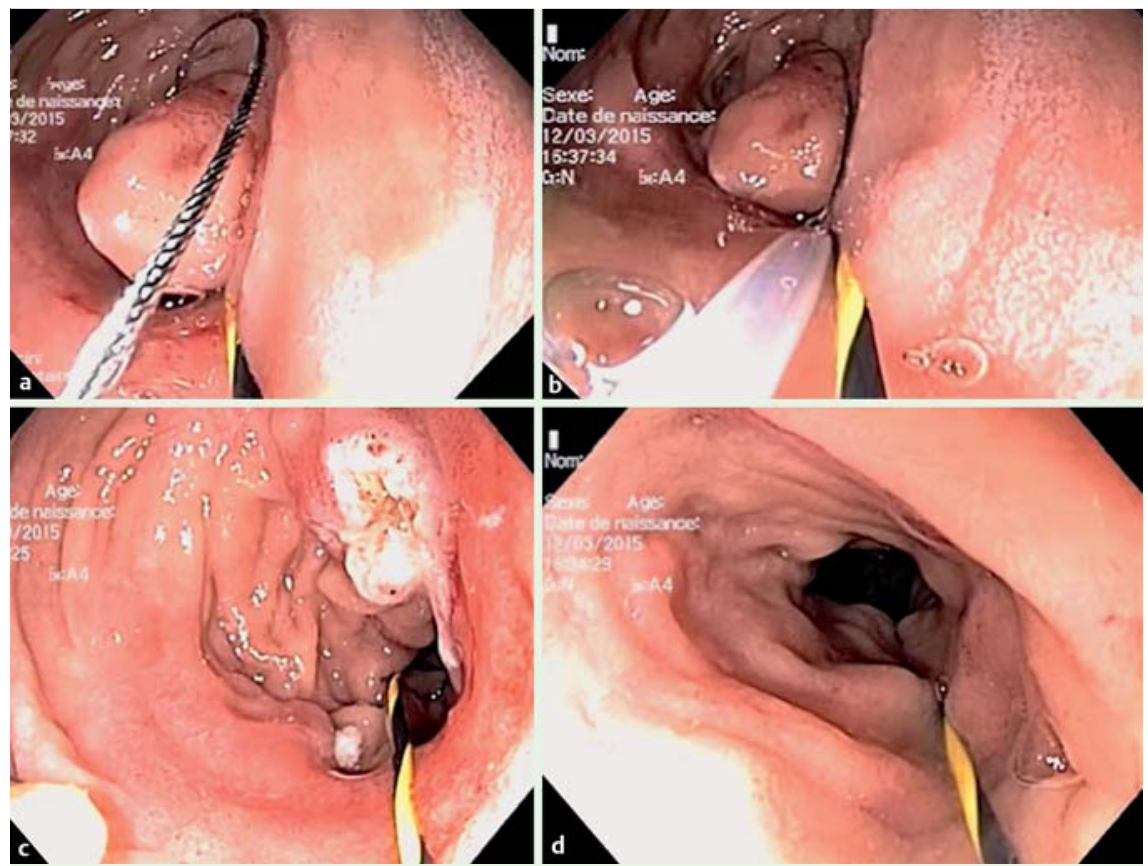

Fig. 4 Third and final step of endoscopic treatment, 8 weeks after the procedure shown in $\bullet$ Fig. 3. Endoscopic mucosal resection of an invaginated growth involving one-quarter of the circumference of the second duodenal portion, and complete patency of the duodenal lumen at the end of treatment.
Pablo Miranda-García, Juan Ignacio Tellechea, Jean Michel Gonzalez, Adrian Culetto, Marc Barthet

Gastroenterology Department, North Hospital, University of The Mediterranean, Marseille, France

Bibliography

DOI http://dx.doi.org/

10.1055/s-0034-1392654

Endoscopy 2015; 47: E442-E443

(c) Georg Thieme Verlag KG

Stuttgart · New York

ISSN 0013-726X

\section{Corresponding author}

\section{Pablo Miranda-García, MD, PhD}

Gastroenterology Department

North Hospital

University of The Mediterranean

Chemin des Bourrely

13915 Marseille

France

Fax: +33-4-91380000

pmpablomiranda@gmail.com 